\title{
Políticas de educação do campo: avanços e desafios
}

\section{Rural education policies: advances and challenges}

\author{
Telmo Marcon*
}

Resumo: O texto analisa as diretrizes da educação do campo numa dupla perspectiva: avanços e desafios. Os avanços evidenciam-se na formulação de diretrizes com base numa concepção de educação emancipatória e cidadã, e os desafios, por sua vez, concretizam-se nas dificuldades de a escola do campo problematizar os contextos socioculturais dos seus alunos; na implementação de políticas de nucleação por governos estaduais e municipais que resultam no deslocamento de escolas do campo para as cidades ou pequenos povoados; no transporte diário de milhares de crianças do campo para a cidade, que, além retirar os sujeitos dos seus contextos, incrementa processos migratórios e colide frontalmente com as diretrizes da educação do campo elaboradas no início do século XXI. Do ponto de vista teórico, o texto assenta-se em documentos e em referenciais bibliográficos relativos à educação do campo.

Palavras-chave: Educação do campo. Diversidade cultural. Políticas educacionais.

\begin{abstract}
This article analyzes the guidelines for rural education from the double perspective of its advances and challenges. On the one hand, advances can be clearly seen in the development of guidelines based on a conception of an emancipative and citizen-oriented education. On the other hand, the challenges are evident in the difficulties faced by rural schools in terms of dealing with the socio-cultural context of their students; the implementation of state and municipal nucleating policies that result in the displacement of schools from rural areas to cities or small villages; and commuting thousands of children from rural areas to the city, which, besides driving subjects away from their contexts, also fosters migratory processes and collides with the guidelines for rural education established in the early XXI century. From the theoretical viewpoint, our work is grounded on documents and bibliographical references concerning rural education.
\end{abstract}

Keywords: Rural education. Cultural diversity. Educational policies.

* Professor do Programa de Pós-Graduação da Faculdade de Educação da Universidade de Passo Fundo (UPF). E-mail: <telmomarcon@upf.br> 


\section{Considerações iniciais}

A história das políticas de educação do campo revela um paradoxo: de um lado, um país caracterizado historicamente como agrícola e que muito pouco se ocupou com a educação do campo; de outro, a preocupação com diretrizes e políticas de educação do campo, exatamente num contexto de expansão da urbanização, de intensa migração do campo para a cidade e da nucleação de escolas nas cidades ou em pequenos povoados. Evidente que essas políticas não estão isoladas de um contexto mais amplo de interesses, disputas políticas e de transformações da sociedade brasileira e mundial. A educação do campo ganha destaque no contexto de reconhecimento da existência de novos sujeitos desde o final do século XX, no período posterior à Constituição de 1988 e à LDB de 1996, como é o caso de indígenas, negros, quilombolas, outras populações do campo.

A consolidação de políticas de educação após a Constituição de 1988 ocorreu com a multiplicação de diretrizes, emendas constitucionais, pareceres e resoluções em vários níveis e modalidades. Conforme Arroyo, Caldart e Molina (2004, p. 14), os movimentos sociais desempenharam um papel decisivo nos rumos das políticas educacionais, no caso, da educação do campo. "No vazio e na ausência dos governos os próprios movimentos tentam ocupar esses espaços, mas cada vez mais cresce a consciência do direito e a luta pela Educação do Campo como política pública". Não há dúvida de que os movimentos sociais, de modo particular o Movimento dos Sem-Terra (MST), desempenharam um papel central nesse debate e na colocação da educação do campo em pauta. A realização da conferência nacional "Por uma educação básica do campo", em 1998, e a segunda conferência nacional "Por uma educação do campo", realizada em 2004, foram fundamentais para os desdobramentos das políticas de educação do campo. Do ponto de vista formal, deram-se avanços substanciais; do ponto de vista concreto, permanecem muitos desafios especialmente porque persistem problemas estruturais históricos que intervêm nas práticas sociais, comprometendo as transformações.

No presente texto, pretende-se analisar os avanços ocorridos na formulação das políticas de educação do campo e alguns obstáculos que limitam a efetivação do que está expresso nas diretrizes. Procurando superar uma leitura romântica sobre o campo, aprofundam-se elementos que o constituem na sua diversidade e complexidade. O desafio teórico está em reconhecê-lo como espaço plural e contraditório que se estrutura dentro de uma totalidade social, embora mantenha características específicas em relação ao contexto urbano. Buscando dar conta dessas preocupações, o texto tem a seguinte estrutura: a) inicia problematizando a forma subordinada do campo em relação à cidade; b) analisa a legislação que trata da educação do campo (diretrizes e pareceres); c) aprofunda 
dois conceitos importantes para a educação do campo: cultura e experiência; d) aponta para alguns desafios na efetivação de uma educação do campo crítica e transformadora; e) tece considerações finais.

\section{Subordinação do campo à cidade}

Não é nenhuma novidade que o campo, no Brasil, ficou marginalizado pelas políticas sociais e educacionais, em especial com a crescente urbanização desde a década de 1930. O Parecer 36/2001, que trata das "Diretrizes operacionais para a educação básica nas escolas do campo" (BRASIL, CNE/CEB, 2001, p. 2) e que dá sustentação para a formulação das "diretrizes da educação do campo", reconhece que o Estado em sua condição de formulador de políticas praticamente desconsiderou o campo, concebendo-o como extensão do urbano.

Por sua vez, a partir de uma visão idealizada das condições materiais de existência na cidade e de uma visão particular do processo de urbanização, alguns estudiosos consideram que a especificidade do campo constitui uma realidade provisória que tende a desaparecer, em tempos próximos, face ao inexorável processo de urbanização que deverá homogeneizar o espaço nacional. Também as politicas educacionais, ao tratarem o urbano como parâmetro e o rural como adaptaşão reforçam essa concepșão. (BRASIL, CNE/CEB, 2001, p. 2, grifo nosso).

José de Souza Martins, na introdução da obra "A militarização da questão agrária no Brasil", faz uma análise dos problemas decorrentes de uma interpretação equivocada da relação urbano-rural. $\mathrm{O}$ autor registra que houve, no estudo do processo político brasileiro e da crise política atual (década de 1980), a predominância "dos interesses das classes e dos grupos sociais urbanos [...]. Não só o estudo, mas também a prática política, dominada pelas classes urbanas, mostram um imprudente desprezo pelas lutas, hoje cotidianas, entre os trabalhadores rurais e os grandes proprietários de terra" (MARTINS, 1985, p. 9). Martins (1985, p. 12) afirma ainda:

É uma tentativa de questionar uma leitura deformada pelo privilegiamento político e teórico do contratual, urbano e salarial. Um Marx mal digerido tem sustentado não poucas confusões entre lugar histórico e lugar político dos assalariados da indústria e dos trabalhadores do campo (gostaria de falar em camponeses, na boa tradição das línguas latino-americanas, certo de que isso não confundiria as pessoas inteligentes, não lhes sugerindo que se trata do camponês europeu pré-capitalista). Todos nós sabemos que a classe operária tem um lugar central no processo histórico, particularmente no deciframento teórico da historicidade do homem. Mas isso não quer dizer que ela tenha o monopólio político do processo histórico. 
Essas reflexões propostas por Martins continuam muito atuais e são importantes para a superação das perspectivas teóricas que trabalham de forma polarizada cidade e campo, privilegiando a primeira em detrimento do segundo. Ao se destacar a relação capital-trabalho como um fenômeno essencialmente do capitalismo urbano-industrial, perde-se de vista que existem relações contraditórias que perpassam a sociedade. Aliás, a relação capital-trabalho faz-se presente, também, no campo de inúmeras formas. Em decorrência dessa interpretação equivocada, historicamente, idealizou-se o campo como lugar belo e natural, mas tendendo a desaparecer. Segundo o Parecer 36/2001, (BRASIL, CNE/CEB, 2001, p. 2), a interpretação do campo como lugar bucólico, que foi construída no passado, comprometeu uma compreensão crítica das contradições. Uma análise crítica do campo não permite tratá-lo, diz o documento, com tom de nostalgia e de um passado que está presente em parte da literatura, "posição que subestima a evidência dos conflitos que mobilizam as forças econômicas, sociais e políticas em torno da posse da terra no país".

Um segundo problema, daí decorrente, é que o campo deixou de ser olhado a partir daquilo que o constitui, ou seja, das suas características, possibilidades, conflitos e contradições. As formas múltiplas de organização social, política, de trabalho e produção, os movimentos sociais com suas reivindicações e lutas assumem características próprias no contexto do campo. Olhar para essas experiências unicamente pela mediação do urbano, além de criar problemas de análise e compreensão, deixa de apreender a dinâmica própria do campo e as múltiplas dimensões existentes. Por outro lado, há que se cuidar para não produzir uma interpretação inversa, ou seja, que privilegia o urbano em sua concepção hegemônica, sob pena de pensar o campo como realidade em si mesma.

No caso brasileiro, a tendência de valorizar mais o urbano em detrimento do rural fica evidente no conjunto das políticas sociais e educacionais implementadas, especialmente no período pós-1930, quando o urbano começava a tornar-se hegemônico, pelo menos do ponto de vista econômico-industrial. As políticas sociais e educacionais formuladas pós-1930 voltam-se essencialmente para as demandas urbanas, conforme o Parecer 36/2001 (BRASIL, CNE/CEB, 2001, p. 5),

A introdução da educação rural no ordenamento jurídico brasileiro remete às primeiras décadas do século $\mathrm{XX}$, incorporando, no período, o intenso debate que se processava no seio da sociedade a respeito da importância da educação para conter o movimento migratório e elevar a produtividade no campo. A preocupação das diferentes forças econômicas, sociais e políticas com as significativas alterações constatadas no comportamento migratório da população foi claramente registrada nos annaes dos Seminários e Congressos Rurais realizados naquele período. 
Dessa constatação, pode-se concluir que o campo aparece nas políticas de modo subordinado ao urbano. A educação do campo, conforme assinala o parecer, visa a contribuir para estancar as migrações para a cidade e não em promover uma educação capaz de pensar as dinâmicas do campo, as suas possibilidades de sobrevivência digna e cidadã. O Parecer 36/2001 reconhece que existem relações de subordinação do rural ao urbano. A esse respeito, continua o documento:

Há, no plano das relações, uma dominação do urbano sobre o rural que exclui o trabalhador do campo da totalidade definida pela representação urbana da realidade. Com esse entendimento, é possível concluir pelo esvaziamento do rural como espaço de referência no processo de constituição de identidades, desfocando-se a hipótese de um projeto de desenvolvimento apoiado, entre outros, na perspectiva de uma educação escolar para o campo. (BRASIL, CNE/CEB, 2001, p. 18).

A ausência de uma análise das dinâmicas e transformações em curso comprometeu não apenas a compreensão do campo, mas também a formulação de políticas sociais e educacionais para dar conta da diversidade e das complexas relações construídas ao longo da história. Conforme veremos na sequência, as diretrizes da educação do campo dão um passo decisivo em relação às políticas existentes até então.

\section{Políticas de educação do campo}

A LDB de 1996 incorporou, no texto final, um conjunto de questões que, até aquele momento, não haviam sido objeto das políticas educacionais e nem reconhecidas como relevantes pela sociedade. Mesmo com todas as disputas corporativas que se fizeram presentes durante a elaboração da LDB, houve avanços em direção à construção de uma proposta de educação para o país contemplando dimensões como a diversidade socioeconômica e étnico-cultural. Essa perspectiva já havia sido incorporada na Constituição de 1988 que, pela primeira vez, reconheceu formalmente que o país é plural, tanto étnica como culturalmente. $\mathrm{Na}$ LDB, essa pluralidade está expressa nas diretriz̧es específicas para a educação de grupos étnico-culturais, como é o caso de afrodescendentes, quilombolas, indígenas, do campo, etc. O art. 28 da LDB (BRASIL, 1996) refere que "na oferta de educação básica para a população rural, os sistemas de ensino promoverão as adaptações necessárias à sua adequação às peculiaridades da vida rural e de cada região [...]". Essa adequação à vida rural inclui os "conteúdos curriculares e metodologias apropriadas às reais necessidades e interesses dos alunos da zona rural", a organização da escola com a adequação do calendário "à natureza do trabalho na zona rural". 
Essas linhas gerais apontadas pela LDB ganham, na primeira década do século XXI, formulações substanciais através de diretrizes específicas para as diferentes modalidades e níveis da educação. A elaboração de pareceres e resoluções tratando da educação em diferentes níveis e modalidades - indígena, especial, educação das relações étnico-raciais infantil, educação de jovens e adultos, do campo, entre outras - é expressão do reconhecimento da diversidade existente na sociedade e, além disso, que a educação precisa dar conta dessa diversidade. A participação do Conselho Nacional de Educação e da Câmara de Educação Básica, assim como a colaboração de importantes entidades e organizações socioeducacionais, foi decisiva para a produção dessa documentação, entre as quais, as diretrizes da Educação do campo que mais interessa no momento.

Os avanços contidos na Constituição de 1988 (BRASIL, 1988) e na LDB de 1996 em relação à educação são expressivos no que tange às políticas anteriores. Uma análise das constituições brasileiras permite concluir que, até a década de 1930, a educação em geral foi tratada de modo periférico, descolada de qualquer projeto mais amplo de sociedade e sem uma participação efetiva do Estado. Mesmo que a Constituição de 1824 estabelecesse que a educação primária fosse "gratuita a todos os Cidadãos", na realidade, ela não passou de uma falácia por duas razões: em primeiro, porque nem todos os brasileiros eram tratados como cidadãos e, em segundo, porque os interesses contrários aos investimentos públicos na educação sempre estiverem presentes e efetivaram-se na Lei $n^{\circ} 16$, de 12 de agosto de 1834, que trata, entre outros assuntos, da "instrução pública e estabelecimentos próprios a promovê-la". As assembleias provinciais passaram a desempenhar essa função, e o Estado desresponsabilizou-se.

É no contexto dos anos de 1930 que a educação passou a ter um destaque maior no conjunto das políticas sociais e educacionais. Setores urbanos foram contemplados com várias políticas sociais, leis trabalhistas e políticas educacionais, enquanto o campo permaneceu à margem. A educação rural ganhou, no contexto em pauta, um tratamento complementar de adequação às políticas educacionais voltadas ao meio urbano, de modo especial, em relação ao calendário escolar e ao currículo. O Parecer da Câmara de Educação Básica, n. 36 de 2001 reconheceu esse problema histórico quando destacou que, de um modo geral, "as Constituições dos Estados abordam a escola no espaço do campo determinando a adaptação dos currículos, dos calendários [...]" (BRASIL, CNE/CEB, 2001, p. 11).

Mesmo com os avanços ocorridos na educação, desde a década de 1930, o campo manteve-se numa condição de subordinado à cidade. No entanto, essa tendência começou a ser superada com os avanços da sociedade civil desde a década de 1980, em especial pelo papel dos movimentos e das organizações sociais do campo que colocou em pauta reivindicações sociais, econômicas e políticas, 
entre as quais a reforma agrária, a aposentadoria, a saúde, a melhoria de salários, a política agrícola e, mais recentemente, as reivindicações de uma política educacional própria.

Não resta dúvida de que as mobilizações sociais ocorridas nas décadas de 1980 e 1990 foram fundamentais para as conquistas educacionais, parte delas incorporadas à Constituição de 1988 e à LDB de 1996. Mesmo com esses avanços, não há, na Constituição de 1988, referências específicas à educação do campo. Há, sim, a afirmação da educação como "direito de todos e dever do Estado e da família", expressa no artigo 205. O artigo 187, inciso IV, trata da política agrícola, mas não fala em educação e sim em "assistência técnica e extensão rural”.

O Parecer n. 36/2001 (BRASIL, CNE/CEB, 2001) sublinha que, após a promulgação da Constituição Federal, algumas constituições estaduais avançaram na formulação de políticas próprias para a educação do campo. O estado do Paraná tem-se destacado nessa empreitada, com a organização de comissões e grupos de estudo promovendo diversos encontros para aprofundar a legislação existente e construir diretrizes para a educação do campo específica para o Paraná. ${ }^{1}$ Ainda, segundo o referido parecer, outro estado que se destacou nessas discussões foi o Rio Grande do Sul, que incorporou a educação do campo na Constituição estadual. O mesmo Parecer (BRASIL, CNE/CEB, 2001, p. 11) anota que essa Constituição estadual foi a única da federação que "inscreve a educação do campo no contexto de um projeto estruturador para o conjunto do país". Além disso, continua o documento, essa Constituição articula ensino agrícola com a implantação da reforma agrária e, com isso, "supera a abordagem compensatória das políticas para o setor e aponta para as aspirações de liberdade política, de igualdade social, de direito ao trabalho, à terra, à saúde e ao conhecimento dos(as) trabalhadores (as) rurais" (BRASIL, CNE/CEB, 2001, p. 11).

Contudo, é preciso avaliar com cautela esse princípio constitucional, visto que o Rio Grande do Sul vem implantando, desde o início dos anos de 1990, políticas de nucleação de escolas nas cidades. O governador Alceu Colares (1991 a 1994) estabeleceu políticas de nucleação de escolas, decisão que impacta diretamente na educação tendo em vista o fechamento de muitas escolas do campo. Essa decisão política nega radicalmente a política de educação implantada pelo governador Leonel Brizola (1959-1963), segundo a qual em toda comunidade

\footnotetext{
1 O Governo do Paraná, através da Coordenação da Educação do Campo, órgão da Secretaria da Educação, tem realizado importantes encontros para discutir e aprofundar a educação do campo. Desse trabalho, resultaram em publicações, entre as quais as sínteses dos três encontros realizados: o primeiro, em 12 de abril de 2008, o segundo, em 17 de maio de 2008, e o terceiro, em 14 de junho de 2008. Em 2006, foi publicado pelo Governo do Estado, pela Secretaria da Educação e pela Superintendência da Educação, um documento denominado "Diretrizes curriculares da educação do campo". Esse material está disponível no portal do governo do Estado do Paraná (http://www.educadores.diaadia.pr.gov.br/arquivos/File/diretrizes/diretriz_edcampo. pdf) e representa um avanço importante em relação aos outros estados.
} 
rural deveria haver pelo menos uma escola (QUADROS, 2002, p. 317-345). Com a nucleação, houve um esvaziamento das escolas do campo e, atualmente, muitas delas fecharam e outras já foram demolidas. Em contrapartida, foi expandido o sistema de transporte escolar que leva, diariamente, milhares de crianças das suas casas e de seus contextos socioculturais para estudarem em escolas localizadas nas cidades ou nos pequenos povoados. Os impactos educacionais, socioculturais e mesmo econômicos precisam ser avaliados em maior profundidade com novas pesquisas. O que se nota, de um modo geral, é que fechamento da escola rural acaba concorrendo para o êxodo de famílias, o que resulta, inclusive, no desaparecimento de algumas comunidades.

Conforme observação anterior, a LDB de 1996 não trata a educação do campo do mesmo modo que aborda a educação indígena e afrodescendente, por exemplo. No entanto, ela avançou em relação ao reconhecimento de que o campo possui características, necessidades e interesses específicos. Segundo o Parecer 36/2001, o legislador inova

Ao submeter o processo de adaptação à adequação, institui uma nova forma de sociabilidade no âmbito da política de atendimento escolar em nosso país. Não mais se satisfaz com a adaptação pura e simples. Reconhece a diversidade sócio-cultural e o direito à igualdade e à diferença, possibilitando a definição de diretrizes operacionais para a educação rural sem, no entanto, recorrer a uma lógica exclusiva e de ruptura com um projeto global de educação para o país. (BRASIL, CNE/CEB, 2001, p. 17).

O reconhecimento de que o campo possui características diferenciadas do contexto urbano é um passo importante. A ruptura com a concepção de que o campo é extensão, ou reflexo, do urbano possibilita considerá-lo nas suas peculiaridades, dinâmicas e potencialidades. Por isso, é relevante ressaltar o avanço do Parecer 36/2001 da Câmara de Educação Básica na compreensão do campo e, por conseguinte, os desafios que precisam ser levados em consideração na formulação das diretrizes:

O que está em jogo é definir, em primeiro lugar, aquilo no qual se pretende ser incluído, respeitando-se a diversidade e acolhendo as diferenças sem transformá-las em desigualdades. A discussão da temática tem a ver, neste particular, com a cidadania e a democracia, no âmbito de um projeto de desenvolvimento onde as pessoas se inscrevem como sujeitos de direitos. Assim, a decisão de propor diretrizes operacionais para a educação básica do campo supõe, em primeiro lugar, a identificação de um modo próprio de vida social e de utilização do espaço, delimitando o que é rural e urbano sem perder de vista o nacional. (BRASIL, CNE/CEB, 2001, p. 18). 
Duas questões merecem destaque: em primeiro, o reconhecimento da diversidade que implica, do ponto de vista epistemológico, a existência do campo com identidade própria, embora não isolado; em segundo, a necessidade de aprofundar os modos de vida dos sujeitos que vivem no campo. O desafio é pensar o campo a partir daquilo que o constitui, as suas características, as contradições e os conflitos. O risco, segundo o Parecer 36/2001, é de transformar a escola do campo em um ente estranho aos sujeitos, ou seja, a escola portar-se como extensão do contexto urbano. $\mathrm{O}$ problema dessa concepção, dominante historicamente, consigna o Parecer, apoiado em estudos de Arroyo, é "propor a adaptação de um modelo único de educação aos que se encontram fora do lugar, como se não existisse um movimento social, cultural e identitário que afirma o direito à terra, ao trabalho, à dignidade, à cultura e à educação" (BRASIL, CNE/ CEB, 2001, p. 19, grifos do autor).

A tentativa de homogeneizar as práticas educativas para todos os sujeitos é um equívoco histórico. Por outro lado, reconhecer o campo como um espaço plural com múltiplos sujeitos e identidades e com experiências próprias não é um procedimento simples. O parecer levanta, na parte final, uma questão fundamental quando considera que o campo não é algo isolado do contexto socioeconômico e político local, nacional e internacional. Esse cuidado é fundamental para que o campo não seja romantizado como se tivesse existência própria, independente dos processos sociais. De acordo com o Parecer n. 36/2001: "Há traços do mundo urbano que passam a ser incorporados no modo de vida rural, assim como há traços do mundo camponês que resgatam valores sufocados pelo tipo de urbanização vigente" (BRASIL, CNE/CEB, 2001, p. 20).

A Resolução n. 01/2002 (BRASIL, CNE/CEB, 2002) adota a mesma postura, ressaltando que os sujeitos que vivem no campo constroem suas experiências, identidades e memórias nos contextos onde vivem e nas relações que estabelecem. No art. $2^{\circ}$, \único, tem-se:

A identidade da escola do campo é definida pela sua vinculação às questões inerentes à sua realidade, ancorando-se na temporalidade e saberes próprios dos estudantes, na memória coletiva que sinaliza futuros, na rede de ciência e tecnologia disponível na sociedade e nos movimentos sociais em defesa de projetos que associem as soluções exigidas por essas questões à qualidade social da vida coletiva no país.

O contexto do campo possui uma grande diversidade de realidades, de experiências socioculturais e produtivas. As lógicas que orientam as relações sociais de vizinhança, as festas, as tradições religiosas, entre outras, possuem dinâmicas específicas. Daí a necessidade, em conformidade com a referida resolução, artigo $5^{\circ}$, da educação do campo abarcar a diversidade em todas as suas dimensões: 
As propostas pedagógicas das escolas do campo, respeitadas as diferenças e o direito à igualdade e cumprindo imediata e plenamente o estabelecido nos artigos 23, 26 e 28 da Lei 9.394, de 1996, contemplarão a diversidade do campo em todos os seus aspectos: sociais, culturais, políticos, econômicos, de gênero, geração e etnia.

$\mathrm{O}$ artigo $8^{\circ}$ das diretrizes da educação do campo trata das "parcerias estabelecidas visando ao desenvolvimento de experiências de escolarização básica e de educação profissional" que deverão dar conta também, conforme inciso segundo, das "atividades curriculares e pedagógicas para um projeto de desenvolvimento sustentável”. Essa tem sido uma preocupação dos movimentos sociais do campo e faz parte da proposta de educação do Movimento dos Sem-Terra. No "Caderno de Educação" (MST, 1999, p. 7) quando trata da "Educação para o trabalho e cooperação", registra:

O que defendemos através deste princípio é a relação necessária que a educação e a escola devem ter com os desafios do seu tempo histórico. No caso das práticas educacionais que acontecem no meio rural, essa relação não pode, hoje, desconsiderar a questão da luta pela reforma agrária e os desafios que coloca para a implantação de novas relações de produção no campo e na cidade.

Articular a educação formal com um projeto de desenvolvimento sustentável é, sem dúvida, um dos grandes desafios. No mesmo documento são discutidas as várias dimensões da educação e as articulações entre "processos educativos e processos econômicos". Ao tratar das relações pedagógicas e econômicas diz: "Se o que queremos, afinal, é a transformação deste modelo, não é fugindo das relações econômicas que vamos conseguir isso [...]”. (MST, 1999, p. 18)

A Resolução n. 01/2002 (BRASIL, CNE/CEB, 2002), artigo 10, ressalta a importância de um trabalho integrado entre as diversas forças sociais existentes, através de uma gestão democrática que assegure e articule "as relações da escola com a comunidade local, com os movimentos sociais, os órgãos normativos do sistema de ensino e os demais setores da sociedade". Nos últimos anos, os movimentos sociais colocaram em pauta, de modo cada vez mais incisivo, a educação formal. Cresce a convicção de que a escola tem um papel importante na formação crítica e cidadã, bem como na formulação de projetos alternativos. No entanto, é preciso articular experiência e educação, ou seja, é necessário, conforme o artigo 13, inciso II, elaborar

Propostas pedagógicas que valorizem, na organização do ensino, a diversidade cultural e os processos de interação e transformação do campo, a gestão democrática, o acesso ao avanço científico e tecnológico e respectivas contribuições para a melhoria das condições de vida e a fidelidade aos princípios 
éticos que norteiam a convivência solidária e colaborativa nas sociedades democráticas (BRASIL, CNE/CEB, 2002).

Para responder satisfatoriamente a esses desafios é fundamental o trabalho dos professores. As diretrizes preveem uma política para uma formação qualificada de professores que atuam nas escolas do campo, bem como uma remuneração digna, além de materiais e equipamentos necessários. O artigo 15 destaca estas dimensões:

I. as responsabilidades próprias da União, dos Estados, do Distrito Federal e dos Municípios com o atendimento escolar em todas as etapas e modalidades da Educação Básica, contemplada a variação na densidade demográfica e na relação professor/aluno;

II. as especificidades do campo, observadas no atendimento das exigências de materiais didáticos, equipamentos, laboratórios e condições de deslocamento dos alunos e professores apenas quando o atendimento escolar não puder ser assegurado diretamente nas comunidades rurais;

III. remuneração digna, inclusão nos planos de carreira e institucionalização de programas de formação continuada para os profissionais da educação que propiciem, no mínimo, o disposto nos artigos 13, 61, 62 e 67 da LDB (BRASIL, CNE/CEB, 2002).

Contrariando uma compreensão equivocada de que a educação do campo pode ser dada de qualquer forma, desde que o profissional tenha vocação e boa vontade, as diretrizes afirmam a necessidade de uma qualificação básica e também de uma formação continuada. As relações campo-cidade no contexto do desenvolvimento capitalista atual exigem uma compreensão global dos processos socioeconômicos e político-culturais, assim como das formas específicas como se desdobram nas diferentes regiões e nas realidades do campo. As diretrizes atribuem à educação do campo a função de ajudar os alunos a compreenderem os seus contextos para atuarem criticamente como cidadãos. Para que isso ocorra, é fundamental entender como as relações capitalistas de produção construídas nos espaços urbanos adentram o campo, e como a globalização hegemônica interfere na cultura e na experiência dos que vivem no campo. Tudo isso exige um grande esforço e capacidade por parte dos profissionais da educação.

Com base nas discussões feitas até este ponto, fica evidente que as diretrizes afirmam a importância da educação do campo. No entanto, isso não é suficiente. É essencial que a educação do campo seja feita, prioritariamente, nas próprias comunidades e, em segundo lugar, que as realidades socioculturais das comunidades sejam conhecidas e trabalhadas nas salas de aula. Somente dessa forma a escola pode tornar-se uma instituição significativa para os sujeitos. 


\section{Cultura e experiência no campo}

Inúmeras pesquisas vêm mostrando que a vida no campo tem suas particularidades em relação ao mundo urbano. Pesquisas como as de Brandão e Freire são reveladoras dos modos de vida dos sujeitos que vivem no campo e, conforme já apontaram pesquisas como as de Grzybowski (1990), Martins (1988, 1989) e Gohn (2001, 2003, 2005), Souza (2006, 2007), Arroyo, Caldart e Molina (2004), entre outras, o campo precisa ser estudado com profundidade a partir das suas dinâmicas e não de um modo genérico e externo. As realidades são complexas e variadas, pois as experiências são construídas no cotidiano e historicamente. Os modos de vida que pescadores constroem nas relações com os rios, os lagos ou o mar são muito distintos dos pequenos agricultores que vivem em regiões de serrado; o cortador de cana constrói suas experiências de modo diverso das dos produtores de uva na região da serra no Rio Grande do Sul; a realidade dos grandes proprietários de terra é muito diferente dos que não têm terra. Os exemplos multiplicam-se.

As pesquisas realizadas por Brandão sobre os modos de modos de vida de camponeses revelam a profundidade das experiências que eles realizam nos espaços onde atuam e as relações que estabelecem entre si, com a natureza, os animais, as divindades etc. $\mathrm{Na}$ obra "O trabalho do saber: cultura camponesa e escola rural", o autor aprofunda várias dessas questões. Num trecho, ele aponta:

Falo aqui de atores culturais cuja vida está muito envolvida por um contato intenso e cotidiano com a natureza [...]. Pais e alunos, todas as pessoas que convoco aqui e que têm algum envolvimento com a educação escolar são homens da roça e vivem do trabalho agropastoril. Nada mais justo do que começar um estudo sobre como os pais viveram no passado e como os filhos vivem hoje o complicado ofício do estudo na escola pelo mundo de símbolos e vivências que lhes é tão afetiva e profissionalmente próximo. Crescer é um acontecimento da natureza. A experiência cotidiana do campesinato é um interminável assistir ao drama de trajetórias de diferentes ciclos entre a vida e a morte. (BRANDÃO, 1990, p. 28).

A vida do campo aproxima, de modo sistemático, o trabalho, a reprodução da vida, as relações sociais e as dinâmicas da própria natureza. É nos seus distintos espaços que os sujeitos acompanham de perto o desenvolvimento da natureza, as estações, as florações, os desfolhamentos, ou, como sintetiza Brandão, são os ciclos da vida e da morte. A escola tem de ser capaz de refletir e aprofundar as implicações dessas realidades e como elas constituem modos de vida, de pensar e agir. Tudo isso intervém na construção das identidades e na própria socialização. Brandão (1990, p. 171) destaca que a escola é uma instituição que socializa, embora não seja a única: 
A socialização do indivíduo na sociedade camponesa (e, portanto, seus momentos de incorporação em culturas) não se realiza somente no interior de agências e de relações intencionalmente dirigidas à inculcação de habitus, à reprodução de modalidades de saber e de participação em processos de formação de identidades e de modos de vida. Tanto do ponto de vista subjetivo quanto do ponto de vista objetivo da cultura, o que está em jogo são várias teias de relacionamento entre tipos de agências e categorias de atores. Em espaços diversos e em diferentes situações, sucessivas ou contemporâneas, ora essas agências e atores sem complementam e se aliam na orientação da conduta e na formação da identidade, ora, concorrem e, aberta ou veladamente, hostilizam-se pela acumulação de capital simbólico e pela reprodução do poder legítimo de aplicação do seu saber e seus valores.

A relação dos sujeitos que vivem no campo com o tempo também merece relevo. Longe de uma visão linear de tempo, eles acompanham diretamente as temporalidades que se expressam nas distintas formas de como a natureza transforma-se ou o próprio movimento do sol e da lua. As temporalidades fazem parte do cotidiano e intervêm diretamente na constituição dos modos de vida. O início e o fim do dia são acompanhados pelo percurso do sol, assim como, na escuridão da noite ou na luz do luar, é possível experienciar dimensões que a vida urbana não permite ou, pelo menos, dificulta. Embasados em observações empíricas, sujeitos que vivem no campo fazem previsões do tempo, prognosticando chuva ou sol, frio ou calor, considerando-se, pois, que essas dimensões são constitutivas dos universos simbólico-culturais dos que lá vivem.

Uma educação contextualizada, conforme propõem as diretrizes da educação do campo, exige capacidade e sensibilidade para aprofundar essas questões. Hoje, é preciso ir além e buscar outros referenciais que ajudem a compreender as transformações que estão ocorrendo em decorrência do desenvolvimento tecnológico e incidindo nos modos de vida. A introdução do relógio e outros recursos tecnológicos transformam a cultura e os modos de compreender o mundo; contudo, essas transformações não podem ser vistas como eliminadoras das culturas. O que estamos experienciando, na atualidade, é uma velocidade maior nas mudanças. Conforme apontou Williams, as culturas passam por transformações nos contextos das relações de dominação, assim como provocam a emergência de práticas e valores novos. A esse respeito, Williams (1979, p. 126) escreve: "Como estamos sempre considerando relações dentro do processo cultural, as definições do emergente, bem como do residual, só podem ser feitas em relação com um sentido pleno do dominante". É importante enfatizar esse ponto de vista para evitar uma interpretação equivocada que considera qualquer transformação como sendo a perda da cultura e da identidade, ressaltando-se, dessa forma, que os modos de vida e as culturas são dinâmicos. 
Os conceitos de campo e de cultura possuem vínculos muito estreitos. Inicialmente, conforme Williams (1969, p. 18), a cultura foi pensada como tendência de crescimento natural, vinculada à dinâmica da agricultura. Ao longo dos séculos, ganhou novos significados e, no final do século XIX, passou a denotar também "um sistema de vida, no seu aspecto material, intelectual e espiritual". O autor aprofunda o conceito de cultura "como um processo social constitutivo, que cria modos de vida específicos e diferentes" (WILLIAMS, 1979, p. 25). Essa perspectiva é importante para a compreensão da cultura do campo e das experiências que os distintos sujeitos que vivem nele constroem e reconstroem.

As pesquisas desenvolvidas por Edward Thompson possibilitam aprofundar ainda mais as vinculações entre cultura e experiência. Ele observa que as pessoas constroem as suas experiências considerando-as como sentimento e "lidam com esses sentimentos na cultura, como normas, obrigações familiares e de parentesco, e reciprocidades, como valores ou na arte e convicções religiosas..." (THOMPSON, 1981, p. 189). Nessa linha de reflexão, enfoca detidamente os elementos que constituem a experiência e assinala que ela é

constituída por sistemas densos complexos e elaborados pelos quais a vida familiar e social é estruturada e a consciência social encontra realização e expressão [...]: parentesco, costumes, as regras visíveis e invisíveis da regulação social, hegemonia e deferência, formas simbólicas de dominação e resistência, fé religiosa e impulsos milenaristas, maneiras, leis, instituições e ideologias tudo o que, em sua totalidade, compreende a genética de todo o processo histórico, sistemas que reúnem todos, num certo ponto, na experiência humana comum, que exerce ela próprio (como experiências de classe peculiares) sua expressão sobre o conjunto. (THOMPSON, 1981, p. 189).

Assim, cultura e experiência são constitutivas dos sujeitos e precisam ser compreendidas em suas dinâmicas e historicidades. Quando se trata do campo, essas dimensões se fazem presente, por vezes, de forma contraditória. A própria linguagem, como mediadora entre os sujeitos, é marcada por essa historicidade, de tal forma que, sendo socialmente construída, a linguagem é fundamental para compreender a cultura e a experiência e não pode ser entendida como um reflexo das condições materiais da vida, mas como expressão da própria vida material. Williams concebe a linguagem como consciência prática e, como tal,

está saturada por toda atividade social e a satura, inclusive a atividade produtiva. E, como essa compreensão é social e contínua (em distinção dos encontros abstratos do 'homem' e 'seu mundo', ou a 'consciência' e 'realidade', ou 'linguagem' e 'existência material'), ela ocorre dentro de uma sociedade ativa e em transformação [...]. Ou, mais diretamente, a linguagem é a articulação dessa experiência ativa e em transformação; uma presença social e dinâmica do mundo. (WILLIAMS, 1979, p. 43). 
Nessa linha de reflexão, destacam-se as contribuições de Freire que, em toda a sua obra perpassa uma preocupação com a linguagem dos oprimidos. A sua proposta pedagógica tem um compromisso político de transformar as culturas oprimidas em culturas emancipadas, tendo como base as experiências e as linguagens dos diferentes sujeitos envolvidos nos distintos processos educativos. $\mathrm{Na}$ "Pedagogia do Oprimido" (FREIRE, 1981), decorre uma crítica sistemática aos modos como os oprimidos apropriam-se da linguagem e dos valores da cultura dominante, ou seja, dos opressores. A "Pedagogia do Oprimido" ressalta o papel do oprimido na tomada de consciência dessa situação em vista da transformação da cultura e na afirmação da identidade do oprimido como sujeito. As experiências de alfabetização de adultos, desenvolvidas por ele, mostraram ser possível e viável uma pedagogia centrada no oprimido e nos elementos constitutivos do seu universo simbólico-cultural. Segundo Brandão (1981), a alfabetização, para Freire, não é um processo mecânico e artificial, mas toma como ponto de partida a linguagem e as palavras significativas que constituem o universo simbólico-cultural dos sujeitos. As palavras carregam significados que são construídos nas relações sociais e nos espaços onde os sujeitos vivem. Essa é uma dimensão significativa para pensar a realidade do campo e da educação escolar.

Ao mesmo tempo em que a educação do campo necessita reconhecer e trabalhar com as dimensões anteriormente apontadas (cultura, experiência e linguagem), é importante evitar idealizações dessas dimensões, visto que elas não têm razão e sentido em si. Stuart Hall enfatiza um aspecto que deve ser contemplado em todas as circunstâncias que essas questões estiverem em pauta. Ele pondera que "não existem culturas inteiramente isoladas e paradigmaticamente fixadas, numa relação de determinismo histórico, a classes inteiras - embora existam formações culturais de classe bem distintas e variáveis". Não existindo culturas isoladas, conclui o autor, "as culturas de classe tendem a se entrecruzar e a se sobrepor num mesmo campo de luta” (HALL, 2003, p. 262). Essa compreensão permite aprofundar a tese de que as culturas não estão isoladas, especialmente no contexto atual, em que os meios de comunicação de massa e as tecnologias também se fazem presentes no campo. As culturas não podem ser idealizadas porque elas constituem-se em meio às tensões e às contradições socioeconômicas, políticas e culturais. O desafio está em compreender e aprofundar as implicações da tese de Thompson (1981, p. 190) de que a "luta de classe é ao mesmo tempo uma luta acerca de valores", ou seja, as culturas são permeadas por conflitos e contradições.

Dentro desse panorama, a educação escolar tem de ser capaz de entender e problematizar as culturas, as experiências e as linguagens, posto que, caso contrário, a escola continuará utilizando uma linguagem estranha e tratando de experiências e culturas alheias aos sujeitos do campo e, por conseguinte, 
reproduzindo uma educação bancária, no sentido dado por Freire (1981). Para tanto, é imprescindível partir das experiências que dão sentido para os sujeitos, conforme propõe o próprio Freire, ou da prática social, como postula Saviani (1984). Mesmo que esses autores tenham diferentes compreensões sobre como isso deva ocorrer, ambos reforçam uma tese básica: a escola não pode constituirse num ente estranho aos modos de vida dos sujeitos. Na verdade, a escola deve partir da realidade para problematizá-la em vista do empoderamento ${ }^{2}$ dos sujeitos para assumirem os seus papéis históricos e constituírem-se como cidadãos.

A educação do campo pressupõe, portanto, a compreensão das diferentes formas como o campo é constituído. Como já foi apontado, existem múltiplas experiências sendo construídas cotidianamente e, desse reconhecimento, decorrem alguns desafios. Um deles é a necessidade de fortalecer a pesquisa como possibilidade de qualificar a educação escolar do campo. A pesquisa precisa ajudar a compreender o particular do campo dentro de um contexto de totalidade, ou seja, tem que analisar as práticas específicas de cada contexto numa perspectiva de totalidade dialética, conforme Cury (1987) e Kosik (1985). Em segundo lugar, é imprescindível a qualificação dos métodos de ensino, uma vez que o aluno deve ser sujeito da educação escolar. O método não pode desconsiderar a cultura, as experiências e as linguagens que os alunos constroem e utilizam cotidianamente, e, para tanto, é importante que a escola trabalhe a riqueza de experiências existentes. Contudo, o trabalho de contextualização exige um empenho coletivo e um grande esforço teórico-metodológico. Apreender a realidade, especialmente as questões que envolvem a cultura, demanda o domínio de referenciais teóricos críticos e adequados.

Com base nas contribuições de Freire (1981, 2000), Saviani (1984) e Hurtado (1993), Brandão $(1983,1995)$, entre outros, tem-se que a educação deve ser crítica e emancipatória, capaz de valorizar e transformar a cultura e as práticas sociais. A prática social, ou seja, a cultura na sua concretude deve permear qualquer proposta pedagógica, assim como o conhecimento sistematizado não pode constituir-se em um processo estranho aos alunos; as experiências concretas não podem ser negadas. O conhecimento sistematizado precisa dialogar com as realidades concretas. Segundo Freire (1981, p. 57), “os oprimidos, nos vários momentos da sua libertação, precisam reconhecer-se como homens, na sua vocação ontológica e histórica de ser mais. A reflexão e a ação se impõem, quando não se pretende, erroneamente, dicotomizar o conteúdo da forma histórica".

A emancipação torna-se possível na medida em que a escola trabalhar dentro de uma perspectiva de totalidade e de práxis. De acordo com Freire

\footnotetext{
${ }^{2}$ Mesmo não sendo um conceito elaborado especificamente por Freire e Saviani, o empoderamento perpassa as propostas e as concepções de educação desses educadores: a emancipação dos oprimidos e a construção de uma prática social crítica, coerente e orgânica.
} 
(1981, p. 32), a libertação do oprimido não vem por acaso, mas pela consciência e pela luta dos oprimidos.

Quem, melhor que os oprimidos, se encontrará preparado para entender o significado terrível de uma sociedade opressora? Quem sentirá, melhor do que eles, os efeitos da opressão? Quem, mais que eles, para ir compreendendo a necessidade da libertação? Libertação a que não chegarão pelo acaso, mas pela práxis de sua busca; pelo conhecimento e reconhecimento de lutar por ela. Luta que, pela finalidade que lhe derem os oprimidos, será um ato de amor, com o qual se oporão ao desamor contido na violência dos opressores, até mesmo quando esta se revista da falsa generosidade referida (FREIRE, 1981, p. 32).

Muitas vezes, considera-se que as realidades urbanas são complexas, dando a entender que a realidade rural é simples; porém, essa visão é equivocada por várias razões: em primeiro lugar, porque não há contextos isolados e, em segundo, porque a diversidade de realidades do campo expressa-se nas questões climáticas e geográficas, nas atividades produtivas, nos grupos e nas classes sociais, na diversidade sociocultural, nos hábitos alimentares e no vestuário, nos níveis de instrução, na integração aos processos industriais urbanos, na dependência do sistema financeiro (bancos), na presença dos recursos tecnológicos, entre outros. Como pensar uma educação do campo no contexto dessas complexas realidades?

Outro desafio essencial para a educação escolar do campo diz respeito à presença da escola nas próprias comunidades. A lei assegura uma escola de qualidade no espaço onde os sujeitos vivem e atuam; no entanto, o que está ocorrendo, em alguns estados do Brasil, é um processo inverso. Trata-se de intensos movimentos de nucleação de escolas que, em algumas comunidades, literalmente deslocam, todos os dias, os alunos para as escolas nas cidades ou nos pequenos povoados. O problema é que a escola urbana tem se mostrado resistente em pensar as realidades do campo, ou seja, a criança ou o adolescente vai para a cidade estudar conteúdos estranhos ao seu universo sociocultural.

A nucleação de escolas não aparece com tanto destaque nas diretrizes da educação do campo, mas foi retomada, em 2007, através do Parecer n. 23 (BRASIL, CNE/CEB, 2007) e na Resolução n. 2, de 28 de abril de 2008 (BRASIL, $\mathrm{CNE} / \mathrm{CEB}, 2008)$, que "estabelece diretrizes complementares, normas e princípios para o desenvolvimento de políticas públicas de atendimento da Educação Básica do Campo". Nesse documento, artigo 30, lê-se: "A Educação Infantil e os anos iniciais do Ensino Fundamental serão sempre oferecidos nas próprias comunidades rurais, evitando-se os processos de nucleação de escolas e de deslocamento das crianças". O parágrafo $1^{\circ}$ desse artigo observa que, excepcionalmente os cinco primeiros anos do ensino fundamental poderão ser oferecidos em escolas nucleadas. Além disso, o artigo 5", parágrafo primeiro, determina que "Sempre 
que possível, o deslocamento dos alunos, como previsto no caput, deverá ser feito do campo para o campo, evitando-se, ao máximo, o deslocamento do campo para a cidade". Tanto a Resolução n. 01/2002 (BRASIL, CNE/CEB, 2002) quanto a Resolução n. 02/2008 (BRASIL, CNE/CEB, 2008), artigo $7^{\circ}, \mathbb{S} 1^{\circ}$, tratam do compromisso na organização e no funcionamento das escolas do campo no sentido de respeitar "as diferenças entre as populações atendidas quanto à sua atividade econômica, seu estilo de vida, sua cultura e suas tradições".

A perspectiva das políticas de educação do campo desafia a pensar as realidades e as comunidades do campo a partir delas e das relações que estabelecem. Daí, a necessidade de buscar referenciais que deem conta da análise da realidade, bem como das propostas pedagógicas. Campo e cidade constituem uma totalidade que se desenvolve de forma contraditória, de modo que qualquer tentativa de homogeneização, isolamento ou determinação de uma sobre outra não consegue apreender as especificidades de ambos e os elementos que se entrecruzam, ou seja, que são comuns. Williams (1989) mostra como a cidade vai se constituindo como espaço de referência socioeconômica, cultural e política no capitalismo e busca impor-se sobre o campo. No entanto, o campo não é passivo nessa relação.

\section{Considerações finais}

No âmbito da educação formal do campo, é preciso avançar muito. São muitas as evidências, algumas das quais foram consideradas no presente texto, que atestam o domínio do urbano sobre o rural. A estrutura de escola, o material didático, a formação dos professores, as políticas de nucleação são alguns desses aspectos. Os avanços nas políticas enfrentam esses desafios ao reconhecer o campo como um espaço sociocultural com características próprias, e os educadores precisam estar bem preparados para que, conjuntamente com a disponibilidade de materiais didático-pedagógicos adequados, seja possível transformar a escola num espaço democrático e de cidadania.

Ao concluir o presente artigo, sai fortalecida a convicção de que a educação do campo, na forma como está formulada do ponto de vista legal, representa um avanço político importante, mas apresenta imensos desafios do ponto de vista prático e pedagógico. Os avanços obtidos devem-se muito à participação intensa de movimentos sociais, especialmente os movimentos que surgiram nas décadas de 1980 e 1990. As lutas por direitos sociais e econômicos foram, progressivamente, estendidas à educação. Assim, o Movimento dos Sem-Terra, organizações e movimentos indígenas e afrodescendentes, o Movimento dos Atingidos por Barragens, entre outros, foram colocando em pauta a necessidade de uma educação escolar capaz de empoderar os sujeitos nas lutas por justiça e cidadania. 
A escola do campo precisa, em primeiro lugar, afirmar-se no espaço do campo. Em continuidade, deve constituir-se em um espaço relevante para a reflexão e a construção de conhecimentos articulados com as realidades dos alunos. É fundamental pensar de uma forma propositiva tais realidades, bem como das comunidades do campo e outras questões envolvendo a produção da sobrevivência e a construção de projetos alternativos e sustentáveis. A escola pode contribuir nesse processo na medida em que ajudar a aprofundar as complexas relações que se estabelecem no campo.

É importante destacar que a formulação das políticas é um passo inicial. Esse passo já foi dado, pelo menos em linhas gerais. O desafio é passar do plano da formulação para o aprofundamento de experiências que não podem ser pontuadas por envolverem relações que também são globais. A contribuição de experiências positivas pode dar um suporte para qualificar as pesquisas necessárias, avançar na metodologia de ensino, na elaboração de materiais adequados, na qualificação da infraestrutura, no desenvolvimento de hábitos alimentares sadios, a partir da merenda escolar produzida na própria comunidade, e na formação de professores comprometidos com a educação do campo. Nesse contexto, ganham sentido as pesquisas sobre movimentos e organizações sociais do campo, experiências de educação formal e não formal, a educação popular etc. Tudo isso está trazendo significativas contribuições para repensar a educação escolar. A presença de mestrandos e doutorandos oriundos de movimentos e organizações sociais do campo em programas de pós-graduação stricto sensu é um indicativo de que a pesquisa está sendo reconhecida como essencial e deverá contribuir para a qualificação da educação do campo como um todo. Dessas pesquisas, deverão resultar materiais didático-pedagógicos que contribuirão para qualificar o ensino e também fortalecer as identidades dos sujeitos do campo. Ainda são muitos os preconceitos contra as populações do campo e, nesse aspecto, a qualificação do ensino escolar é, certamente, uma das condições para sua superação.

Com base na discussão feita no presente texto, a partir da bibliografia e da documentação, fica evidente que não se pode falar em educação do campo sem a presença da escola no campo. Nesse sentido, urge uma crítica contundente às iniciativas governamentais (estados e municípios) que retiram a escola do campo e deslocam, diariamente, os alunos para as escolas nucleadas sob o pretexto de economizar recursos e dar uma educação de qualidade para todos. Em primeiro lugar, esse discurso precisa ser desconstruído e os interesses subjacentes desvelados; segundo, é fundamental aprofundar os impactos da nucleação na formação sociocultural das crianças e dos adolescentes e nas comunidades.

Finalmente, uma consideração sobre a formação de professores que atuam ou irão atuar na educação do campo. Nesse caso, evidencia-se, através da história da educação brasileira, que, sem uma decisão política clara de investir na educação, 
dificilmente obteremos avanços. É capital uma decisão política para formar professores qualificados e preparados para compreenderem as contradições mais amplas da sociedade capitalista e das realidades do campo, em particular, e ajudarem os alunos a se situarem no mundo atual. A formação básica precisa dar os suportes epistemológicos, teóricos e pedagógicos para fundamentar uma compreensão do campo no contexto das relações contraditórias da sociedade capitalista. À formação continuada cabe a função de refletir sobre os avanços e as dificuldades encontradas nos processos educativos. A práxis coloca-se, nessa perspectiva, como condição: refletir a ação em vista de uma ação mais qualificada.

\section{Referências}

ARroyO, M. G.; CALDART, R. S.; MOLINA, M. C. (Orgs.). Por uma educação do campo. Petrópolis: Vozes, 2004.

BRANDÃO, C. R. O que é método Paulo Freire. São Paulo: Brasiliense, 1981.

. Casa de escola: cultura camponesa e educação rural. Campinas: Papirus, 1983.

. O trabalho do saber: cultura camponesa e escola rural. São Paulo: FTD, 1990.

_. Em campo aberto: escritos sobre a educação e a cultura popular. São Paulo: Cortez, 1995.

BRASIL. Constituição da República Federativa do Brasil. Brasília: Senado, 1988.

Lei n. 9394/96. Estabelece as diretrizes e bases da educação nacional. Brasília, 1996.

. CNE/CEB. Parecer n. 36/2001. Diretrizes Operacionais para a Educação Básica nas Escolas do Campo. Brasília, 2001.

CNE/CEB. Resolução n. 01/2002. Institui Diretrizes Operacionais para a Educação Básica nas Escolas do Campo. Brasília, 2002.

CNE/CEB. Parecer n. 23/2007. Consulta referente às orientações para o atendimento da Educação do Campo. Brasília, 2007.

CNE/CEB. Resolução n. 2, de 28 de abril de 2008. Estabelece as diretrizes complementares, normas e princípios para o desenvolvimento de políticas públicas de atendimento da Educação Básica do Campo. Brasília, 2008.

CURY, C. R. J. Educação e contradição: elementos metodológicos para uma teoria crítica do fenômeno educativo. 3. ed. São Paulo: Cortez, 1987.

FREIRE, P. Pedagogia do oprimido. 9. ed. Rio de Janeiro: Paz e Terra, 1981.

Pedagogia da autonomia: saberes necessários à prática educativa. 15. ed. São Paulo: Paz e Terra, 2000.

GOHN, M. da G. História dos movimentos e lutas sociais: a constituição da cidadania dos brasileiros. 2. ed. São Paulo: Loyola, 2001.

(Org.). Movimentos sociais no início do século XXI: antigos e novos atores sociais. Petrópolis: Vozes, 2003. 
O protagonismo da sociedade civil: movimentos sociais, ONGs e redes solidárias. São Paulo: Cortez, 2005.

GRZYBOWSKI, C. Caminhos e descaminhos dos movimentos sociais no campo. 2. ed. Petrópolis: FASE, 1990.

HALL, S. Notas sobre a desconstrução do 'popular'. In: HALL, S. Da diáspora: identidades e mediações culturais. Belo Horizonte: EdUFMG; Brasília: UNESCO, 2003. p. 247-263.

HURTADO, C. N. Educação para transformar, transformar para educar. Petrópolis: Vozes, 1993.

KOSIK, K. Dialética do concreto. 3. ed. Rio de Janeiro: Paz e Terra, 1985.

MARTINS, J. de S. A militarização da questão agrária no Brasil. Petrópolis: Vozes, 1985.

. Não há terra para plantar neste verão: o cerco das terras indígenas e das terras de trabalho no renascimento político do campo. 2. ed. Petrópolis: Vozes, 1988.

. Caminhando no chão da noite: emancipação política e libertação nos movimentos sociais no campo. São Paulo: Hucitec, 1989.

MST. Princípios da educação no MST. Caderno de educação, São Paulo, 1999.

QUADROS, C. de. O Rio Grande coberto de escolas: a ação do governo de Leonel Brizola na educação pública do Rio Grande do Sul (1959-1963). In: BASTOS, M. H. C.; TAMBARA, E.; KREUTZ L. (Org.). Histórias e memórias da educação do Rio Grande do Sul. Pelotas: Seiva, 2002. p. 317-345.

SAVIANI, D. Escola e democracia. 9. ed. São Paulo: Cortez, 1984.

SOUZA, M. A. Educação do campo: propostas e práticas pedagógicas do MST. Petrópolis: Vozes, 2006.

A pesquisa sobre educação e o Movimento dos Trabalhadores Rurais Sem-Terra (MST) nos Programas de Pós-Graduação em Educação. Revista Brasileira de Educação, Rio de Janeiro, v. 12, n. 36, p. 443-461, set./dez. 2007. DOI: 10.1590/S1413-24782007000300005 THOMPSON, E. P. A miséria da teoria ou um planetário de erros: uma crítica ao pensamento de Althusser. Rio de Janeiro: Zahar Editores, 1981.

WILLIAMS, R. Cultura e sociedade 1780 - 1950. São Paulo: Companhia Editora Nacional, 1969.

Marxismo e literatura. Rio de Janeiro: Zahar Editores, 1979.

O campo e a cidade na história e na literatura. São Paulo: Companhia das Letras,

1989.

Recebido em 09/11/2011

Versão final recebida em 10/03/2012

Aceito em 17/03/2012 